\title{
Unresectable Hepatoblastoma
}

National Cancer Institute

\section{Source}

National Cancer Institute. Unresectable Hepatoblastoma. NCI Thesaurus. Code C8641.

Hepatoblastoma not amenable to surgical removal. 